\title{
Quantification acuity in spontaneous shoaling decisions of three-spined sticklebacks
}

\author{
Marion Mehlis $^{1} \cdot$ Timo Thünken $^{2}$ Theo C. M. Bakker ${ }^{1} \cdot$ Joachim G. Frommen $^{2}$
}

Received: 17 December 2014/Revised: 28 May 2015/Accepted: 8 June 2015 / Published online: 23 June 2015

(C) Springer-Verlag Berlin Heidelberg 2015

\begin{abstract}
The ability to discriminate between different quantities is widespread throughout the animal kingdom, and the underlying mechanisms of quantity discrimination are currently intensely discussed. In contrast, questions elucidating the limits of quantity estimation received rather little attention so far. Here, we examined fine-tuned quantity estimation in the three-spined stickleback (Gasterosteus aculeatus) in a natural context, i.e. during shoaling decisions. Wild-caught focal fish were given the spontaneous choice between two shoals which differed in group size by 1 fish ( 0 vs. 1,1 vs. 2, 2 vs. 3, 3 vs. 4,4 vs. 5 , 5 vs. 6 and 6 vs. 7), based on visual assessment. The results show that sticklebacks generally prefer to shoal with the larger group. They discriminated numerical contrasts up to 6 versus 7, equalling a numerical ratio of 0.86 . Preference patterns followed Weber's law, i.e. decreased with increasing numerical ratio. This pattern was found across all numerical conditions as well as within the small number range (ranging from 1 vs. 2 to 3 vs. 4). The results suggest that wild-caught three-spined sticklebacks are spontaneously able (i.e. without prior learning) to detect subtle differences in shoal sizes. Further, they confirm findings of
\end{abstract}

Marion Mehlis and Timo Thünken have contributed equally to this work.

\footnotetext{
Timo Thünken

tthuenken@evolution.uni-bonn.de

$\bowtie$ Joachim G. Frommen

joachim.frommen@iee.unibe.ch

1 Institute of Evolutionary Biology and Ecology, University of Bonn, An der Immenburg 1, 53121 Bonn, Germany

2 Department of Behavioural Ecology, Institute of Ecology and Evolution, University of Berne, Wohlenstrasse 50a, 3032 Hinterkappelen, Switzerland
}

previous studies highlighting the contribution of the analogue magnitude system to quantity estimation in fishes.

Keywords Counting - Fishes - Gasterosteus aculeatus . Numerical abilities · Shoaling · Weber's law

\section{Introduction}

The ability to assess different quantities is common throughout the animal kingdom (Cantlon and Brannon 2007). It has been described, for example, in primates (Beran 2001, 2007; Call 2000; Shumaker et al. 2001; Vonk 2003) and other species of mammals (e.g. Baker et al. 2011; Irie-Sugimoto et al. 2009; Kilian et al. 2003; Pisa and Agrillo 2009; Vonk and Beran 2012; Ward and Smuts 2007; West and Young 2002), birds (Garland et al. 2012; Pepperberg 2006; Rugani et al. 2010, 2013), amphibians (Uller et al. 2003; Stancher et al. 2015), fishes (Agrillo et al. 2012a; Gómez-Laplaza and Gerlai 2011) and invertebrates (Evans et al. 2007; Reznikova and Ryabko 2011). The ability to differentiate between different quantities allows individuals to optimally adjust their behaviour and hence to increase their survival or reproduction prospects, for instance by avoiding places with a higher number of predators or by preferring habitats with more food or fewer competitors (see Shettleworth 2009).

It is often assumed that animals (including humans) use similar, ancestral mechanisms for number quantification (Agrillo et al. 2012b; Feigenson et al. 2004; Reznikova and Ryabko 2011). Small quantities $(\leq 4)$ are thought to be processed by a process termed "subitizing" (Kaufman et al. 1949). Here, each item is individually recognized by an "object file system" (OFS). The OFS represents a fast and precise mechanism, which is, however, limited up to four 
entities, probably because of limited capacities of the shortterm memory (Feigenson et al. 2004). Quantities above 4 are thought being processed by an "analogue magnitude system" (AMS), based on ratios (Feigenson et al. 2004). While the AMS is also fast, it is less precise. Furthermore, accuracy is predicted to decrease as the numerical ratio approaches 1, a phenomenon termed Weber's law (GómezLaplaza and Gerlai 2011; Krause et al. 1998; Weber 1905). In accordance, many animals show highly precise discrimination abilities when dealing with numbers smaller than 4 , while their discrimination ability is less precise when quantities are higher (e.g. Agrillo et al. 2007, 2010; Hauser et al. 2003; but see Garland et al. 2012). However, the concept of two distinct discrimination mechanisms has recently been challenged by studies suggesting that the AMS might also be responsible for the estimation of quantities in the subitizing range (e.g. Gallistel and Gelman 1992; Rugani et al. 2013; Stancher et al. 2013; see also Agrillo et al. 2014 and references therein).

Fishes are a frequently used model group for studying proximate and ultimate factors of quantity discrimination (Agrillo et al. 2012a; Gómez-Laplaza 2012; Stancher et al. 2013). A standard way to measure numerical abilities in fishes takes advantage of the innate preference of many fish species to shoal with the larger of two groups in order to reduce predation risk (Bradner and McRobert 2001; Hager and Helfman 1991; Hoare et al. 2004; Krause and Godin 1994). Recent research is focussing especially on the general underlying mechanisms of quantity discrimination (Agrillo et al. 2014; Frommen et al. 2009; Gómez-Laplaza and Gerlai 2011, 2013; Piffer et al. 2013). Generally, most fishes are able to discriminate amounts of 0 versus 1,1 versus 2 and 2 versus 3 (see Gómez-Laplaza 2012 for a review). However, different fish species seem to differ in discrimination accuracy. For instance guppies, Poecilia reticulata, discriminate between 3 versus 4 (Piffer et al. 2012), whereas redtail splitfin fish, Xenotoca eiseni, failed (Stancher et al. 2013). When discriminating numbers above 4 , ratios up to 0.5 , e.g. 3 versus 6 or 5 versus 10 are differentiated by angelfish, Pterophyllum scalare (Gómez-Laplaza 2012), guppies (Piffer et al. 2013) and zebrafish, Danio rerio (Ruhl and McRobert 2005). Mosquitofish, Gambusia affinis (Agrillo et al. 2007), and three-spined sticklebacks, Gasterosteus aculeatus, are also shown to discriminate ratios of 0.66 (e.g. 8 vs. 12 or 40 vs. 60, see Frommen et al. 2009; Thünken et al. 2014). Even more subtle discrimination is described in fathead minnows, Pimephales promelas (Hager and Helfman 1991), which differentiated 18 versus 23, which equals a ratio of 0.78 . However, although accuracy is a crucial component of quantity estimation, this issue was seldom pursued in detail. Knowledge about variation in accuracy may contribute to a comprehensive understanding of quantity estimation and the underlying mechanism in animals.
Thus, the present study aimed to contribute to filling this gap of knowledge, by investigating fine-tuned group size discrimination in three-spined sticklebacks.

The three-spined stickleback, G. aculeatus, is a small fish widely distributed across the Northern Hemisphere. Nonreproductive three-spined sticklebacks form shoals with group sizes ranging from a few to several hundred individuals (Peuhkuri 1998; Poulin 1999; Wootton 1984). Shoaling as an anti-predator response (Magurran 1990) has been intensively studied in this species (Doucette et al. 2004; Godin and Crossman 1994; Krause et al. 1998), and safety is generally expected to increase with increasing group size (Cresswell and Quinn 2011). Accordingly, threespined sticklebacks preferred to shoal with the larger of two relatively small groups at different numerical contrasts, e.g. 3 versus 20, 3 versus 5 (Krause 1993), 5 versus 10, 5 versus 9 (Krause et al. 1998), 8 versus 12 (Frommen et al. 2009) or 3 versus 6 (Fischer and Frommen 2013). Moreover, the results from small groups appear to be transferable to large shoals as sticklebacks preferred groups consisting of 60 fish over groups of 15, 20 and 40 fish (Thünken et al. 2014).

In the present study, we examined whether three-spined sticklebacks show fine-tuned discrimination accuracy between shoal sizes differing in only 1 fish within $(\leq 4)$ and beyond $(>4)$ the subitizing range. Fish were offered the choice between seven different numerical contrasts ranging from 0 versus 1 to 6 versus 7. This includes ratios ranging from 0.5 to 0.86 . Furthermore, we aimed to elucidate whether the strength of the preference for the larger group changes according to the numerical ratio. The OFS hypothesis predicts that quantities $\leq 4$ are discriminated independent of ratio, whereas the AMS hypothesis predicts that discrimination is in general ratio-related.

\section{Materials and methods}

Shoal choice trials took place during three-spined sticklebacks' non-reproductive season in the years 2007, 2008 and 2010 at the Institute for Evolutionary Biology and Ecology, University of Bonn. In each year discrimination between the following group sizes was tested in random order to avoid sequence effects: 0 versus $1(N=30), 1$ versus $2(N=35), 2$ versus $3(N=35), 3$ versus 4 $(N=35), 4$ versus $5(N=35), 5$ versus $6(N=35)$ and 6 versus $7(N=35)$ [from now on termed numerical contrast (NC) 1-7]. This equals ratios of $0.5,0.67,0.75,0.8,0.83$ and 0.86 (1 vs. 2-6 vs. 7).

\section{Experimental fish}

Annually, about 500 individuals were caught prior to the experimental trials from a pond near the institute using 
minnow traps. Fish were kept under natural light conditions in a large outdoor tank (750 1) with constant water flow (flow rate $31 \mathrm{~min}^{-1}$ ). In total, 240 focal fish were used; each focal fish was used only once to avoid pseudoreplication. The remaining fish served to create the stimulus shoals. Stimulus fish were used several times, but never on the same day or in the same shoal combination. Prior to testing, focal and stimulus fish were randomly selected from the outdoor tank and kept separately from each other in group tanks ( $\mathrm{L} 60 \mathrm{~cm} \times \mathrm{W} 30 \mathrm{~cm} \times \mathrm{H} 30 \mathrm{~cm}$ ) in the laboratory under standardized conditions (day length: $8 \mathrm{~h}$ light, $16 \mathrm{~h}$ dark; room temperature $17 \pm 1{ }^{\circ} \mathrm{C}$ ). All fish had an acclimation time of at least $24 \mathrm{~h}$ in the laboratory before they participated in a trial. All individuals were daily fed in excess in the morning with defrosted mosquito larvae (Chironomus spp.) to avoid confounding effects caused by different hunger levels (e.g. Frommen et al. 2007; Krause 1993).

\section{Experimental set-up}

The experimental tank $(80 \mathrm{~cm} \times 40 \mathrm{~cm} \times 45 \mathrm{~cm}$, water height $15.5 \mathrm{~cm}$ ) was divided by transparent Plexiglas partitions into two stimulus compartments $(15 \mathrm{~cm} \times 40 \mathrm{~cm}$ $\times 45 \mathrm{~cm})$ on the right- and left-hand side and a focal compartment in the middle $(50 \mathrm{~cm} \times 40 \mathrm{~cm} \times 45 \mathrm{~cm})$. The partitions were glued to the tank wall. Thus, diffusion of chemical cues between compartments was not possible and quantities had to be visually estimated (cf. Frommen et al. 2009; Thünken et al. 2014). The middle of the experimental tank as well as $12 \mathrm{~cm}$ preference zones in front of each stimulus compartment were indicated by black lines drawn on the side walls and the bottom. To avoid disturbance from outside, a black curtain was stretched around the experimental tank. The set-up was illuminated by a fluorescent tube $(36 \mathrm{~W})$, which was centred lengthwise directly above the aquarium. The trials were recorded from the front using a webcam (Creative WebCam Live!) connected to a laptop behind the curtain.

For each trial, fish were randomly caught from their respective holding tanks using a hand net. After transferring stimulus shoals into their compartments, the focal fish was placed into a transparent Plexiglas cylinder (diameter $10 \mathrm{~cm} \times \mathrm{H} 35 \mathrm{~cm}$ ) in the centre of the experimental tank. To control for potential side effects, the side on which the larger shoal was presented was alternated. After an acclimation time of $2 \mathrm{~min}$, the focal fish was released by carefully lifting the cylinder from behind the curtain using a pulley system. The behaviour of the focal fish was recorded for $10 \mathrm{~min}$ as soon as it had crossed the middle line for the first time. After each trial, the body mass and standard length of all experimental fish were measured and the body condition was calculated as a function of body mass and standard length $[(100 \times$ body mass $) /$ standard length ${ }^{3}$ ], following Bolger and Connolly (1989). Stimulus fish were released in the outdoor tanks, while focal fish were kept in a separated tank. Between trials, the experimental tank was emptied and cleaned to remove chemical traces. Afterwards, the tank was refilled with water which was put in an empty 2001 tank at least $12 \mathrm{~h}$ before testing to adjust the temperature and to remove gases.

\section{Data analysis}

Videos were analysed by one person (MM) blindly with respect to group size differences between the stimulus shoals. The time the focal fish spent in the association zones in front of the stimulus shoals was quantified over a period of 10 min using the time stamp shown in the video. For analyses, the proportion of time (\%) the focal fish spent in each association zone (relative to total time in both zones) was calculated. Statistics were performed with the R. 2.9.1 statistical software package (R-DevelopmentCore-Team 2009). As data were normally distributed according to Shapiro-Wilk tests, linear mixed-effect models (LMEs) were fitted. Tests of statistical significance were based on likelihood ratio tests (LRT), which follow a $\chi^{2}$-distribution. These routines use maximum likelihood parameter estimation. In all fitted models non-significant factors were removed in order of statistical relevance. Thus, reported $P$ values of models refer to the increase in deviance when the respective variable had been removed.

NC 1 (0 vs. 1) served as a control to ensure that focal fish generally preferred to shoal. It was thus analysed separately as it differed from the remaining NCs 2-7 (1 vs. 2-6 vs. 7) due the fact that focal fish had not the choice between two shoals as one stimulus compartment contained no fish. For the NCs 2-7, combined data were analysed first. Proportion of time in the two association zones served as the dependent variable. Shoal size (small/ large) was entered as explanatory variable and focal fish ID as a random factor (to control for the paired experimental set-up). "Tank side" was always entered as a fixed factor to control for potential side preferences unrelated to shoal size. Average standard length and body condition of stimulus shoal fish as well as relative body size and condition of the focal fish in relation to the stimulus fish were added as covariates in the statistical analyses. Neither the mean body size (LME, LRT, $\chi^{2}=1.334$, df $=1$, $P=0.248$ ), body condition of the stimulus shoal (LME, LRT, $\chi^{2}=3.426$, df $=1, P=0.064$ ), nor the relative body size or condition of the focal fish in relation to the stimulus fish (LME, LRT, $\chi^{2}=0.054$, df $=1, P=0.817$ and $\chi^{2}=0.067$, df $=1, P=0.795$, respectively) significantly affected shoal choice and were thus not included in the further analyses. Additionally, to examine whether 
preference for the larger shoal changed according to the numerical ratio, the interaction between "shoal size" (small/large) and "ratio" was examined. This was done for the NCs 2-7 and for the NCs 2-4 (1 vs. 2, 2 vs. 3 and 3 vs. 4) and the NCs 5-7 (4 vs. 5, 5 vs. 6 and 6 vs. 7) separately, to test ratio dependence within and beyond the subitizing number range. Furthermore, all NCs were analysed separately using similar LMEs as described above to examine potential discrimination thresholds.

\section{Results}

Three-spined sticklebacks spent significantly more time near the compartment containing a conspecific than near the empty compartment (NC 1, 0 vs. 1; LME, LRT, $\chi^{2}=150.806$, df $=1, P<0.001$; Fig. 1). Across the other six contrasts, fish spent significantly more time near the larger of the two offered shoals (NCs 2-7; LME, LRT, $\chi^{2}=54.582$, df $=1, P<0.001$; Fig. 1). Analysing these six contrasts separately revealed significant preferences for the larger group in all numerical combinations except in NC 4 (3 vs. 4), where no significant preference could be detected for any shoal size (see Fig. 1; Table 1).

Across NCs 2-7, preference for the larger group decreased with increasing numerical ratio (group size $\times$ ratio, LME, LRT, $\chi^{2}=7.547$, df $=1, P=0.006$; Fig. 2). This relationship was also significant when only including the contrasts within the subitizing number range

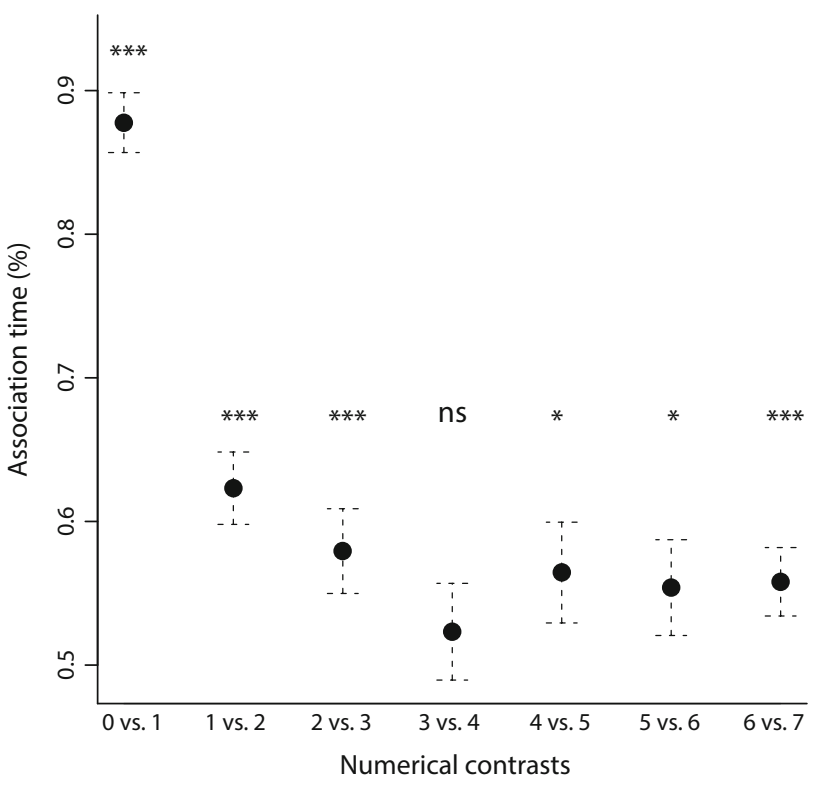

Fig. 1 Mean proportion $\pm \mathrm{SE}$ of time spent near the larger group across the seven different numerical contrasts tested in this study. $P$ values refer to deviation from chance expectation level of 0.5 . $* * * P<0.001 ; * P<0.05$; ns $P>0.05$
(NCs 2-4, 1 vs. 2, 2 vs. 3 and 3 vs. 4; LME, LRT, $\chi^{2}=11.094$, df $=1, P<0.001$, Fig. 2), but not beyond that range (NCs 5-7, 4 vs. 5, 5 vs. 6 and 6 vs. 7; LME, LRT, $\chi^{2}=0.102$, df $\left.=1, P=0.749\right)$.

\section{Discussion}

Three-spined sticklebacks distinguished between differentsized shoals differing in 1 fish and preferred the larger shoal. In particular, they were able to discriminate a shoal consisting of 6 fish from a shoal consisting of 7 fish, which correspond to a numerical ratio of 0.86 . Such a large ratio has to our knowledge not been shown to be discriminated by any other fish species. Within this number range, previous studies on quantity discrimination revealed discrimination abilities in other fish species as well. Still, angelfish P. scalare (Gómez-Laplaza 2012), zebrafish D. rerio and Siamese fighting fish Betta splendens (Agrillo et al. 2012a) or redtail splitfin $X$. eiseni (Stancher et al. 2013) did not differentiate ratios larger than 0.66 (e.g. 2 vs. 3,5 vs. 9, 8 vs. 12). Mosquitofish $G$. affinis and guppies $P$. reticulata discriminated ratios of 0.75 only in the subitizing number range (up to four entities), but failed to do so when quantities were bigger than 4, e.g. 9 versus 12 (Agrillo et al. 2014, 2010). However, it has to be mentioned that different studies were based on different methodological approaches (e.g. trained or spontaneous response, abstract objects or live conspecifics as stimuli) and samples sizes. Using behavioural experiments, cognitive abilities can only be

Table 1 Performance of three-spined sticklebacks in quantity discrimination trials

\begin{tabular}{llrr}
\hline Numerical contrast & Explanatory variable & \multicolumn{1}{c}{$\chi^{2}$} & \multicolumn{1}{c}{$P$} \\
\hline 0 versus 1 & Tank side & 0.278 & 0.598 \\
& Shoal size & 150.806 & $<\mathbf{0 . 0 0 1}$ \\
1 versus 2 & Tank side & 8.051 & $\mathbf{0 . 0 0 5}$ \\
& Shoal size & 39.960 & $<\mathbf{0 . 0 0 1}$ \\
2 versus 3 & Tank side & 8.645 & $\mathbf{0 . 0 0 3}$ \\
& Shoal size & 15.664 & $<\mathbf{0 . 0 0 1}$ \\
3 versus 4 & Tank side & 0.248 & 0.618 \\
& Shoal size & 0.973 & 0.324 \\
4 versus 5 & Tank side & 2.785 & 0.095 \\
& Shoal size & 6.617 & $\mathbf{0 . 0 1 0}$ \\
5 versus 6 & Tank side & 4.377 & $\mathbf{0 . 0 3 6}$ \\
& Shoal size & 5.780 & $\mathbf{0 . 0 1 6}$ \\
6 versus 7 & Tank side & 5.343 & $\mathbf{0 . 0 2 1}$ \\
& Shoal size & 11.650 & $<\mathbf{0 . 0 0 1}$ \\
\hline
\end{tabular}

Results of linear mixed-effect models examining the effect of shoal size (large vs. small) and tank side on shoaling preferences across different numerical contrasts [significant effects $(P<0.05)$ are marked bold] 


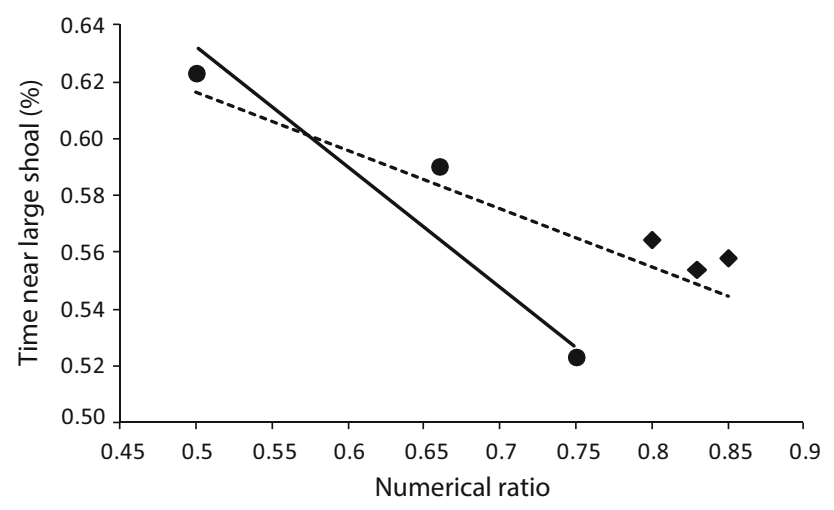

Fig. 2 Mean time spent near the larger shoal in relation to the numerical ratio. Circles represent contrasts within the subitizing range (NCs 2-4), and squares contrasts above the subitizing range (NCs 5-7). Lines represent least-square regression lines [dashed line across all (NCs 2-7); continuous line within subitizing range (NCs 2-4)]

measured indirectly, by examining whether and to which extent animals do discriminate or not. As a consequence, lack of discrimination does not necessarily mean lack of possessing the cognitive abilities to solve a task, as for example, motivation to show a given behaviour might be absent. Therefore, examinations of species differences should optimally control for potential variation in motivational states, which might be particularly pronounced in wild-caught fishes.

In other taxa than fishes, even higher accuracy than in the current study has been shown. Besides adult humans and other primates, which posses highly advanced numerical abilities enabling them to correctly estimate 0.9 ratios (Halberda and Feigenson 2008; Hanus and Call 2007), also North Island robins Petroica longipes differentiated between 7 versus 8 food items, i.e. a 0.875 ratio (Garland et al. 2012). In contrast, bottlenose dolphins Tursiops truncates differentiate numerical contrasts up to 6 versus 7 , but were not able to differentiate between 7 versus 8 (Jaakkola et al. 2005). In our study, the most difficult numerical contrast, i.e. 6 versus 7 was mastered by sticklebacks. Thus, the aim of future experiments should be to clarify the limits of fine-tuned accuracy in this species.

In the present study preferences for the larger group decreased with increasing numerical ratio, i.e. it follows Weber's law. This finding is in accordance with a recently published study, which examined quantity discrimination in large stickleback groups (see Thünken et al. 2014). Interestingly, this relationship was also present within the subitizing range (i.e. NCs 2-4). This is in contrast to the OFS hypothesis, which predicts that small number discrimination is not affected by ratio effects. Thus, the AMS might also contribute to quantity discrimination in sticklebacks in the subitizing range. However, further experiments including further numerical contrasts in the small number range (e.g. 1 vs. 3,1 vs. 4,2 vs. 4 ) are needed to corroborate this conclusion. Also, it would be interesting to know whether the decreased acuity at higher ratios is due to inter-individual differences, i.e. poorer discrimination of certain individuals or due to general effects.

The question whether quantity discrimination is based on numerical abilities or continuous attributes such as density, cumulative surface area or overall space occupied by a group is currently disputed by using sophisticated experimental approaches (see Agrillo et al. 2009; Frommen et al. 2009; Gómez-Laplaza and Gerlai 2013; Piffer et al. 2013). In our case, the larger group might occupy more space or might show a higher density. Thus, instead of using any numerical system, preferences for the larger shoal as shown in the present study might in fact be explained by preferences for the denser shoal. However, it was not the aim of our study to examine the underlying proximate causes of quantity discrimination but to investigate fine-tuned quantification accuracy in a functionally realistic context.

Under natural conditions, sticklebacks' preference for the larger shoal is assumed to be adaptive because individual predation risk is supposed to decrease with increasing shoal size, for instance, due to dilution effects (Foster and Treherne 1981). This benefit of choosing the bigger group should be largest when groups are small, while it is thought to be less important to choose between two rather large groups (Pulliam 1973; Roberts 1996). Accordingly, in the present study the strongest preference and motivation to shoal with the larger group was found in the experimental condition with the largest relative group size differences ( 1 vs. 2$)$, i.e. at the smallest ratio. Furthermore, sticklebacks strongly avoided swimming solitary, as indicated by the result of NC 1 ( 0 vs. 1$)$. However, even at the smallest relative size differences tested (6 vs. 7), sticklebacks' preference should be adaptive because individuals may reduce their predation risk by joining the larger group. Under natural conditions shoal sizes of many other fish species are similar to that tested in the present study (e.g. Agrillo et al. 2007; Hain and Neff 2007). Thus, from a functional perspective, one would expect similar discrimination abilities in other fish species.

While stickleback's preferences for the larger shoal clearly indicated pronounced quantity discrimination abilities, there was an overall great variation in individual shoaling decisions. This variation can be explained by the fact that shoaling decisions in fishes are influenced by a range of factors, including, for example, nutritional state (Reebs and Saulnier 1997), personality type (Cote et al. 2012), body size (Ward and Currie 2013) or reproductive state (Frommen et al. 2012). While we aimed at correcting for some of these factors by including body measures and tank side biases in our analyses and testing fish outside the 
breeding season, others are more difficult to control for. Furthermore, variation in shoaling preference might also be explained by intrinsic differences in individuals' discrimination ability, both within and across species; for example, it might depend on developmental stage. For instance, 6-month-old human children are able to discriminate a ratio of 0.50 ( 8 vs. 16) but not 0.66 (8 vs. 12), whereas 9-month-olds are able to discriminate a ratio of 0.66 but not 0.80 (8 vs. 10, Lipton and Spelke 2003). Similar patterns have been shown in guppies; juveniles discriminate 0.25 and 0.5 ratios but not-in contrast to adults-0.66 ratios (Miletto Petrazzini et al. 2014). Finally, discrimination might be impaired when the total set size is very big as several fish species failed to differentiate between 25 versus 50 objects $(0.5$ ratio) (Agrillo et al. 2012a). Nevertheless, three-spined sticklebacks still discriminated between shoal sizes of 40 versus 60 (a ratio 0.66) (Thünken et al. 2014).

To conclude, the present study showed fine-tuned quantity discrimination accuracy in three-spined sticklebacks. Fish discriminated numerical contrasts of 6 versus 7 , equalling a ratio of 0.86 . Such a highly accurate discrimination has to our knowledge never been observed for another fish species. In addition, we found that preference for the large group decreased with increasing numerical ratio which is in accordance with Weber's law and probably reflects cognitive limitation.

Acknowledgments We are grateful to Rebecca Deutsch, Nicole Ehrenfried, Kathrin Kunz and Juliana Monteiro for their help in conducting the experiments. We thank Ken Cheng and anonymous referees for useful comments on the manuscript. TT was funded by SNF Grant No. 31003A_144191 provided to JGF.

Ethical standard The experiments comply with the current laws of the country in which they were performed.

Conflict of interest The authors declare that they have no competing interests.

\section{References}

Agrillo C, Dadda M, Bisazza A (2007) Quantity discrimination in female mosquitofish. Anim Cogn 10:63-70

Agrillo C, Dadda M, Serena G, Bisazza A (2009) Use of number by fish. PLoS One 4:e62466

Agrillo C, Piffer L, Bisazza A (2010) Large number discrimination by mosquitofish. PLoS One 5:e15232

Agrillo C, Miletto Petrazzini ME, Tagliapietra C, Bisazza A (2012a) Inter-specific differences in numerical abilities among teleost fish. Front Psychol 3:483

Agrillo C, Piffer L, Bisazza A, Butterworth B (2012b) Evidence for two numerical systems that are similar in humans and guppies. PLoS One 7:e31923

Agrillo C, Petrazzini MEM, Bisazza A (2014) Numerical acuity of fish is improved in the presence of moving targets, but only in the subitizing range. Anim Cogn 17:307-316
Baker JM, Shivik J, Jordan KE (2011) Tracking of food quantity by coyotes (Canis latrans). Behav Process 88:72-75

Beran MJ (2001) Summation and numerousness judgments of sequentially presented sets of items by chimpanzees (Pan troglodytes). J Comp Psychol 115:181-191

Beran MJ (2007) Rhesus monkeys (Macaca mulatta) enumerate large and small sequentially presented sets of items using analog numerical representations. J Exp Psychol: Anim Behav Process 33:42-54

Bolger T, Connolly PL (1989) The selection of suitable indices for the measurement and analysis of fish condition. J Fish Biol 34:171-182

Bradner J, McRobert SP (2001) The effect of shoal size on patterns of body colour segregation in mollies. J Fish Biol 59:960-967

Call J (2000) Estimating and operating on discrete quantities in orangutans (Pongo pygmaeus). J Comp Psychol 114:136-147

Cantlon JF, Brannon EM (2007) Basic math in monkeys and college students. PLoS Biol 5:e328

Cote J, Fogarty S, Sih A (2012) Individual sociability and choosiness between shoal types. Anim Behav 83:1469-1476

Cresswell W, Quinn JL (2011) Predicting the optimal prey group size from predator hunting behaviour. J Anim Ecol 80:310-319

Doucette LI, Skulason S, Snorrason SS (2004) Risk of predation as a promoting factor of species divergence in threespine sticklebacks (Gasterosteus aculeatus L.). Biol J Linn Soc 82:189-203

Evans SR, Finnie M, Manica A (2007) Shoaling preferences in decapod crustacea. Anim Behav 74:1691-1696

Feigenson L, Dehaene S, Spelke E (2004) Core systems of number. Trends Cogn Sci 8:307-314

Fischer S, Frommen JG (2013) Eutrophication alters social preferences in three-spined sticklebacks (Gasterosteus aculeatus). Behav Ecol Sociobiol 67:293-299

Foster WA, Treherne JE (1981) Evidence for the dilution effect in the selfish herd from fish predation on a marine insect. Nature 293:466-467

Frommen JG, Luz C, Bakker TCM (2007) Nutritional state influences shoaling preference for familiars. Zoology 110:369-376

Frommen JG, Hiermes M, Bakker TCM (2009) Disentangling the effects of group size and density on shoaling decisions of threespined sticklebacks (Gasterosteus aculeatus). Behav Ecol Sociobiol 63:1141-1148

Frommen JG, Bakker TCM, Proscurcin LC, Mehlis M (2012) Gravidity-associated shoaling decisions in three-spined sticklebacks (Gasterosteus aculeatus). Ethology 118:1149-1156

Gallistel CR, Gelman R (1992) Preverbal and verbal counting and computation. Cognition 44:43-74

Garland A, Low J, Burns KC (2012) Large quantity discrimination by North Island robins (Petroica longipes). Anim Cogn 15:1129-1140

Godin JGJ, Crossman SL (1994) Hunger-dependent predator inspection and foraging behaviours in the threespine stickleback (Gasterosteus aculeatus) under predation risk. Behav Ecol Sociobiol 34:359-366

Gómez-Laplaza LM (2012) Shoal size and shoaling in fish. Indian J Soc Nat Sci 1:7-18

Gómez-Laplaza LM, Gerlai R (2011) Can angelfish (Pterophyllum scalare) count? Discrimination between different shoal sizes follows Weber's law. Anim Cogn 14:1-9

Gómez-Laplaza LM, Gerlai R (2013) Quantification abilities in angelfish (Pterophyllum scalare): the influence of continuous variables. Anim Cogn 16:373-383

Hager MC, Helfman GS (1991) Safety in numbers: shoal choice by minnows under predatory threat. Behav Ecol Sociobiol 29:271-276

Hain TJA, Neff BD (2007) Multiple paternity and kin recognition mechanisms in a guppy population. Mol Ecol 16:3938-3946 
Halberda J, Feigenson L (2008) Developmental change in the acuity of the "Number sense": the approximate number system in 3-, 4-, 5-, and 6-year-olds and adults. Dev Psychol 44:1457-1465

Hanus D, Call J (2007) Discrete quantity judgments in the great apes (Pan paniscus, Pan troglodytes, Gorilla gorilla, Pongo pygmaeus): the effect of presenting whole sets versus item-by-item. J Comp Psychol 121:241-249

Hauser MD, Tsao F, Garcia P, Spelke ES (2003) Evolutionary foundations of number: spontaneous representation of numerical magnitudes by cotton-top tamarins. Proc $R$ Soc $B$ 270:1441-1446

Hoare DJ, Couzin ID, Godin JGJ, Krause J (2004) Context-dependent group size choice in fish. Anim Behav 67:155-164

Irie-Sugimoto N, Kobayashi T, Sato T (2009) Relative quantity judgment by asian elephants (Elephas maximus). Anim Cogn 12:193-199

Jaakkola K, Fellner W, Erb L, Rodriguez M, Guarino E (2005) Understanding of the concept of numerically "less" by bottlenose dolphins (Tursiops truncatus). J Comp Psychol 119:296-303

Kaufman EL, Lord MW, Reese TW, Volkmann J (1949) The discrimination of visual number. Am J Psychol 62:498-525

Kilian A, Yaman S, von Fersen L, Güntürkün O (2003) A bottlenose dolphin discriminates visual stimuli differing in numerosity. Learn Behav 31:133-142

Krause J (1993) The influence of hunger on shoal size choice by three-spined sticklebacks, Gasterosteus aculeatus. J Fish Biol 43:775-780

Krause J, Godin JGJ (1994) Shoal choice in the banded killifish (Fundulus diaphanus, Teleostei, Cyprinodontidae): effects of predation risk, fish size, species composition and size of shoals. Ethology 98:128-136

Krause J, Godin JGJ, Rubenstein D (1998) Group choice as a function of group size differences and assessment time in fish: the influence of species vulnerability to predation. Ethology 104:68-74

Lipton JS, Spelke ES (2003) Origins of number sense: large-number discrimination in human infants. Psychol Sci 14:396-401

Magurran AE (1990) The adaptive significance of schooling as an anti-predator defence in fish. Ann Zool Fenn 27:51-66

Miletto Petrazzini ME, Agrillo C, Piffer L, Bisazza A (2014) Ontogeny of the capacity to compare discrete quantities in fish. Dev Psychobiol 56:529-536

Pepperberg IM (2006) Grey parrot numerical competence: a review. Anim Cogn 9:377-391

Peuhkuri N (1998) Shoal composition, body size and foraging in sticklebacks. Behav Ecol Sociobiol 43:333-337

Piffer L, Agrillo C, Hyde DC (2012) Small and large number discrimination in guppies. Anim Cogn 15:215-221

Piffer L, Miletto Petrazzini ME, Agrillo C (2013) Large number discrimination in newborn fish. PLoS One 8:e62466

Pisa PE, Agrillo C (2009) Quantity discrimination in felines: a preliminary investigation of the domestic cat (Felis silvestris catus). J Ethol 27:289-293

Poulin R (1999) Parasitism and shoal size in juvenile sticklebacks: conflicting selection pressures from different ectoparasites? Ethology 105:959-968
Pulliam HR (1973) Advantages of flocking. J Theor Biol 38:419-422

R-Development-Core-Team (2009) R: a language and environment for statistical computing. R Foundation for Statistical Computing, Vienna

Reebs SG, Saulnier N (1997) The effect of hunger on shoal choice in golden shiners (Pisces: Cyprinidae, Notemigonus crysoleucas). Ethology 103:642-652

Reznikova Z, Ryabko B (2011) Numerical competence in animals, with an insight from ants. Behaviour 148:405-434

Roberts G (1996) Why individual vigilance declines as group size increases. Anim Behav 51:1077-1086

Rugani R, Regolin L, Vallortigara G (2010) Imprinted numbers: newborn chicks' sensitivity to number vs. continuous extent of objects they have been reared with. Dev Sci 13:790-797

Rugani R, Cavazzana A, Vallortigara G, Regolin L (2013) One, two, three, four, or is there something more? Numerical discrimination in day-old domestic chicks. Anim Cogn 16:557-564

Ruhl N, McRobert SP (2005) The effect of sex and shoal size on shoaling behaviour in Danio rerio. J Fish Biol 67:1318-1326

Shettleworth SJ (2009) Cognition, evolution, and behavior. Oxford University Press, Oxford

Shumaker RW, Palkovich AM, Beck BB, Guagnano GA, Morowitz H (2001) Spontaneous use of magnitude discrimination and ordination by the orangutan (Pongo pygmaeus). J Comp Psychol 115:385-391

Stancher G, Sovrano VA, Potrich D, Vallortigara G (2013) Discrimination of small quantities by fish (redtail splitfin, Xenotoca eiseni). Anim Cogn 16:307-312

Stancher G, Rugani R, Regolin L, Vallortigara G (2015) Numerical discrimination by frogs (Bombina orientalis). Anim Cogn $18: 210-229$

Thünken T, Eigster M, Frommen JG (2014) Context-dependent group size preferences in large shoals of three-spined stickleback. Anim Behav 90:205-210

Uller C, Jaeger R, Guidry G, Martin C (2003) Salamanders (Plethodon cinereus) go for more: rudiments of number in an amphibian. Anim Cogn 6:105-112

Vonk J (2003) Gorilla (Gorilla gorilla gorilla) and orangutan (Pongo abelii) understanding of first- and second-order relations. Anim Cogn 6:77-86

Vonk J, Beran MJ (2012) Bears 'count' too: quantity estimation and comparison in black bears, Ursus americanus. Anim Behav 84:231-238

Ward AJW, Currie S (2013) Shoaling fish can size-assort by chemical cues alone. Behav Ecol Sociobiol 67:667-673

Ward C, Smuts BB (2007) Quantity-based judgments in the domestic dog (Canis lupus familiaris). Anim Cogn 10:71-80

Weber EH (1905) Tastsinn und Gemeingefühl. Verlag von Wilhelm Engelmann, Leibzig

West RE, Young RJ (2002) Do domestic dogs show any evidence of being able to count? Anim Cogn 5:183-186

Wootton RJ (1984) A functional biology of the sticklebacks. Croom Helm, London 